\title{
Physiological and Genetic Approaches to Studying Endodormancy-related Traits in Populus
}

\author{
Glenn T. Howe \\ School of Natural Resources, The Ohio Agricultural Research and Development Center, \\ The Ohio State University, Wooster, OH 44691-4096 \\ Joel Davis, Zoran Jeknic, and Tony H.H. Chen ${ }^{1}$ \\ Department of Horticulture, Oregon State University, Corvallis, OR 97331-7304 \\ Barbara Frewen and Harvey D. Bradshaw, Jr. \\ Ecosystem Science and Urban Horticulture Division, College of Forest Resources, University of Washington, \\ Seattle, WA 98195-4115 \\ Purev Saruul \\ Department of Forest Resources, University of Minnesota, St. Paul, MN 55108
}

\begin{abstract}
Received for publication 21 Apr. 1999. Accepted for publication 5 May 1999. We thank Antje Rohde, Jorunn Olsen, Thomas Moritz, and Olavi Junttila for helpful discussions, and Marie Semko-Duncan for help with the manuscript. This work was supported in part by the U.S. Dept. of Agriculture National Research Initiative Competitive Grant Program (grant No. 96-353000-3421) and the National Science Foundation (grant No. IBN-9421420). The cost of publishing this paper was defrayed in part by the payment of page charges. Under postal regulations, this paper therefore must be hereby marked advertisement solely to indicate this fact.

${ }^{1}$ To whom reprint requests should be addressed (phone: 541-737-5444; fax: 541-737-3479; e-mail: chen@ava.bcc.orst.edu).
\end{abstract}

Plants native to boreal, temperate, and subtropical regions are subjected to large seasonal variations in temperature. In these regions, woody perennial plants have evolved annual growth cycles that promote long-term survival and growth. These annual growth cycles involve alternations between active shoot growth and vegetative dormancy (endodormancy) that are closely timed with seasonal changes in the local climate. Dormancy, in general, is defined as the temporary suspension of visible growth of any plant structure containing a meristem (Lang, 1987). Endodormancy, which develops in the fall, is characterized by a requirement for sustained exposure to low, near- 
freezing temperatures before active shoot growth can resume in the spring. This need for exposure to low temperatures is called a chilling requirement. Endodormancy is also referred to as "winter dormancy" or "rest" (Fuchigami and Nee, 1987).

The development of endodormancy is an important adaptive strategy in woody perennial plants and greatly influences their use in both horticulture and forestry. Endodormancy is adaptive because plants are more resistant to freezing and dehydration stress during these periods of relative inactivity. On the other hand, biomass production may be substantially reduced by relatively long periods of dormancy when growth does not occur. Therefore, the length of the dormant period represents a trade-off between winter survival and biomass yield. A greater understanding of endodormancy-related traits would allow us to better match horticultural varieties or seed sources with zones of plant hardiness (Cathey, 1990), breed trees that are more cold hardy, or develop higher-yielding genotypes for use in reforestation (reviewed in Howe et al., 1995).

We define endodormancy-related traits in the broad sense, as traits associated with any aspect of endodormancy induction, maintenance, or release. In some cases, endodormancy-related traits may be associated with endodormancy per se, but in other cases, the association may be indirect. For example, short-day-induced traits are endodormancyrelated because short days (SDs) can induce endodormancy, and because these traits are temporally associated with the induction of endodormancy in nature. Quantitative or semi-quantitative measurements have been made on a number of endodormancy-related traits. These include the timing of spring bud flush (Bradshaw and Stettler, 1995), timing of fall bud set (Riemenschneider et al., 1994), degree of frost hardiness in the spring or fall (Aitken and Adams, 1995), degree of endodormancy (Farmer and Reinholt, 1986), and chilling requirement (Sorensen, 1983). These traits have been well studied because they are clearly adaptive and because they shed light on what is happening at the whole-plant level. In addition, the number of investigations of endodormancy-related biochemical traits has increased in recent years. A number of these biochemical traits will be discussed.

The objectives of this paper are threefold. First, we will introduce the reader to the use of Populus species and hybrids as models for studying the physiology and genetics of endodormancy-related traits in trees. Second, we will discuss approaches for studying endodormancy-related processes and genes, focusing on approaches that will shed light on genetic variation in these traits. We will use examples of our research on endodormancy-related traits in Populus to illustrate these approaches. Finally, we will discuss priorities for future research.

\section{POPULUS SPECIES AND INTERSPECIFIC HYBRIDS ARE GOOD MODELS FOR STUDYING ENDODORMANCY-RELATED TRAITS IN TREES}

In addition to their economic importance, the poplars (poplars, cottonwoods, and aspens) have a number of ecological, physiological, and molecular genetic traits that make them excellent models for studying endodormancy-related traits in trees. First, a number of poplar species, including black cottonwood (Populus trichocarpa Torr. \& Gray) and eastern cottonwood (P. deltoides Bartr.), have extensive latitudinal distributions and contain northern and southern ecotypes that have dramatically different endodormancy-related characteristics (Howe et al., 1995; Pauley and Perry, 1954). Second, the poplars have seasonally indeterminate growth-that is, they will grow continuously under long days (LDs), but will stop growing, form a terminal bud, and become endodormant under SDs (Howe et al., 1995; Jian et al., 1997). In both eastern and black cottonwood, for example, SDs alone are capable of inducing a high degree of bud endodormancy, comparable to that observed under natural outdoor conditions (Jian et al., 1997; G.T. Howe, unpublished results). In addition, because photoperiodic responses in poplar are mediated by photoreceptor proteins called phytochromes (Howe et al., 1996; Olsen et al., 1997b), the poplars are excellent models for studying both the effects of SDs on endodormancy-related traits in general, and the roles of the phytochromes, in particular. Third, the poplars are the fastest-growing trees in the temperate zone and are easy to propagate by root or stem cuttings. The availability of clonal material facilitates destructive sampling and the testing of identical genotypes in multiple environments. Fourth, the poplars are ideal for molecular genetic studies of trees because of their small genome size (Bradshaw and Stettler, 1993), the availability of genetic linkage maps (Bradshaw et al., 1994; Liu and Furnier, 1993), and their ability to be transformed using either biolistics or Agrobacterium-mediated transformation (Charest et al., 1997; Fillatti et al., 1987). Transgenic technology is more advanced in the poplars than in any other forest tree genus. Fifth, interspecific hybridization is relatively easy and useful for capturing hybrid vigor (heterosis) for commercial use, or for producing pedigrees that are desirable for mapping quantitative trait loci (QTLs). Interspecific hybrid pedigrees, for example, have already been used to map QTLs affecting stem growth, spring bud flush, and disease resistance (Bradshaw and Stettler, 1995; Newcombe and Bradshaw, 1996; Newcombe et al., 1996). Finally, the taxonomic relationship between Populus and Arabidopsis thaliana (L.) Heynh. is close enough that information on the molecular genetics of Arabidopsis should be useful for gaining a better understanding of endodormancy-related traits in trees. In fact, this has already been done for a number of putative endodormancy-related genes, including genes encoding the phytochromes and those involved in abscisic acid (ABA) perception (Howe et al., 1998; Rohde et al., 1998, 1999).

\section{PHYSIOLOGICAL VS. GENETIC APPROACHES FOR STUDYING ENDODORMANCY}

Many morphological, physiological, and biochemical changes are associated with endodormancy, including those responsible for the expression of the endodormancy-related traits described above. Although substantial research has been devoted to characterizing many of these changes, we remain largely ignorant of the events that occur at the biochemical level, including changes in gene expression. The general biochemical changes that are associated with endodormancy, including changes in phytohormone levels, have been reviewed (Faust et al., 1997; Lang, 1994; Powell, 1987; Rowland and Arora, 1997). We will focus our discussion on characterizing changes in gene expression and identifying endodormancy-related genes.

Approaches to detecting changes in gene expression and identifying the corresponding genes can be divided into two classes, physiological and genetic. Most of our understanding about endodormancy is derived from physiological approaches that focus on characterizing the morphological, physiological, and biochemical differences between plants that are in different physiological states (e.g., dormant vs. nondormant). Generally, these approaches are based on the hypothesis that the differences that are observed between physiologically different plants are functionally important. Trees with contrasting physiological characteristics can be achieved by exposing the plants to contrasting environmental conditions (Coleman et al., 1991; Jian et al., 1997), sampling the plants at different times in a changing environment (Coleman et al., 1991), or exposing different genotypes to an environment that elicits a different physiological response in each genotype (Arora et al., 1992).

Physiological approaches aimed at identifying endodormancyrelated genes include general analyses of differential gene expression and expression analyses of specific candidate genes. In contrast to the physiological approaches, genetic approaches seek to identify endodormancy-related genes based on their genetic cosegregation with endodormancy-related traits. Genetic approaches include Mendelian genetic analyses and mapping of quantitative trait loci (QTL mapping).

\section{PHYSIOLOGICAL APPROACHES}

\section{The physiology of endodormancy induction, maintenance, and release in Populus}

Because SDs can induce endodormancy (discussed below), photoperiodic responses are important endodormancy-related traits in many tree species. The timing of SD-induced growth cessation and bud set varies among latitudinal ecotypes of Populus. We investigated the 

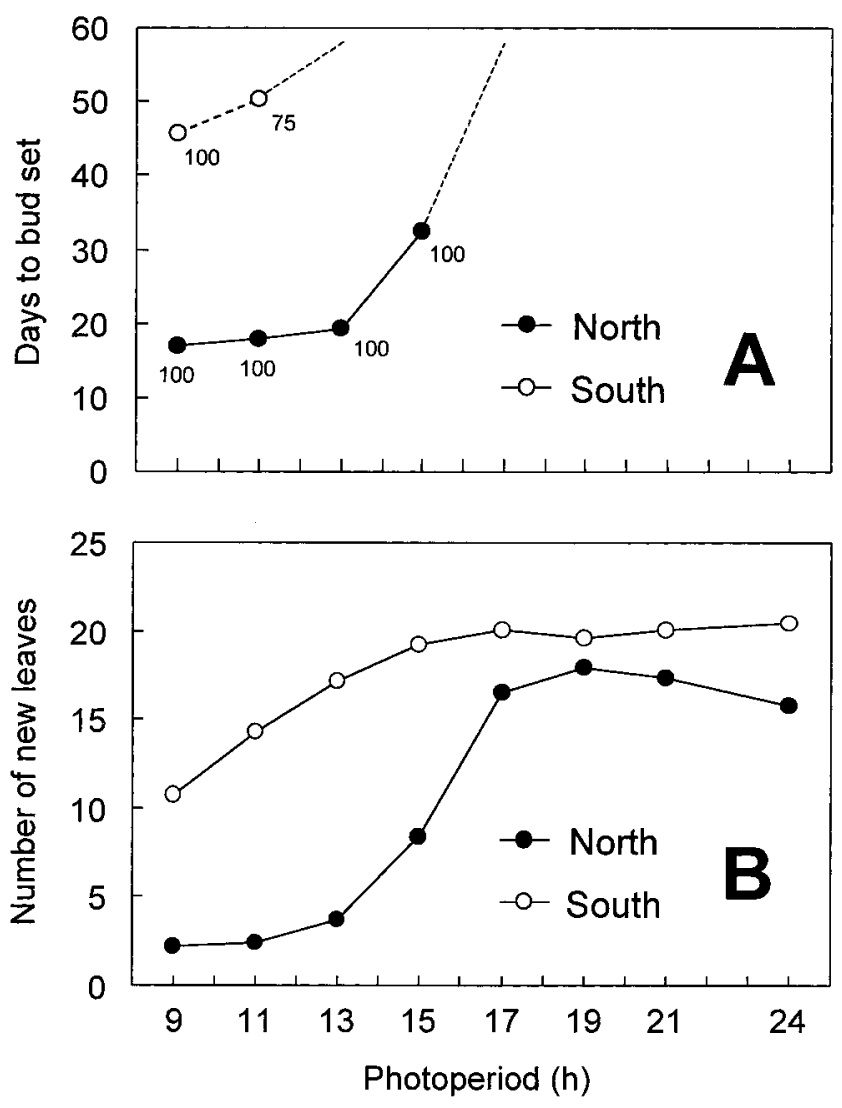

Fig. 1. Photoperiodic responses of a northern (- $(-)$ and a southern $(-\mathrm{O}-$ ) ecotype of black cottonwood (Populus trichocarpa) growing in a greenhouse. For terminal bud set (A), the numerical values are the percentages of trees that formed a permanent or temporary bud during the experiment. Treatments in which all of the trees formed a terminal bud are connected by solid lines and treatments in which some (or all) of the trees were actively growing on the last day of the experiment are connected by dashed lines. The number of new leaves (B) represents the number of newly visible leaves that appeared from the time that the photoperiodic treatments were initiated until the end of the 53-d experiment (Adapted from Howe et al., 1995).

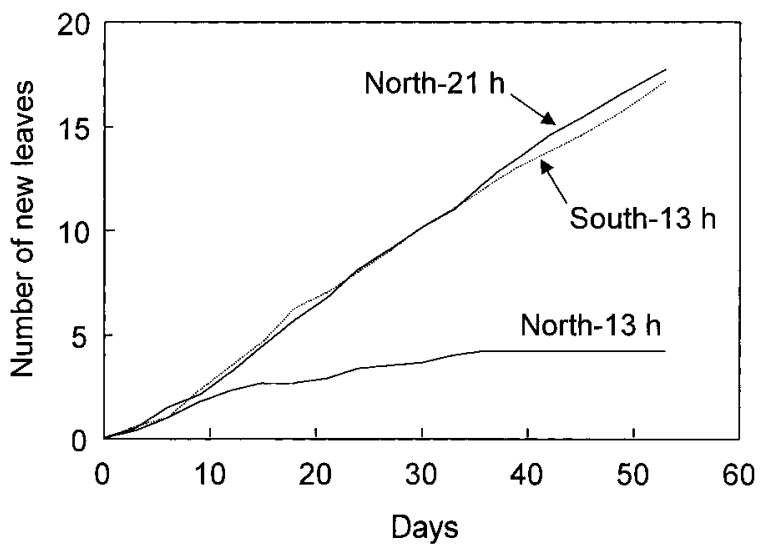

Fig. 2. Growth curves for a northern (-) and a southern (------) ecotype of black cottonwood (Populus trichocarpa) growing under either a 13- or 21$\mathrm{h}$ photoperiod in a greenhouse. photoperiodic responses of two northern $\left(53^{\circ} 35^{\prime}\right.$ and $\left.53^{\circ} 50^{\prime} \mathrm{N}\right)$ and two southern $\left(34^{\circ} 10^{\prime}\right.$ and $\left.40^{\circ} 32^{\prime} \mathrm{N}\right)$ genotypes of black cottonwood by growing trees under a range of photoperiods in the greenhouse (Howe et al., 1995). Although SDs induced bud set in both the northern and southern ecotypes, the northern ecotype had a longer critical photoperiod (i.e., the longest photoperiod that elicited a short-day response) and greater photoperiodic sensitivity (i.e., the change in response per unit change in photoperiod) (Fig. 1 A and B) (Howe et al., 1995). Because of these differences, the southern trees exhibited a significant delay in the timing of bud set compared with the northern trees, even under a 9-h photoperiod (Fig. 1A). We also found that a 13-h photoperiod could be used to obtain maximum discrimination between the photoperiodic responses of the northern and southern ecotypes. Under the 13-h photoperiod, the northern genotypes set bud and stopped growing in $\approx 17 \mathrm{~d}$ (on average), whereas this daylength had little effect on the growth of the southern genotypes (Fig. 2). Therefore, the 13-h photoperiod provides a good experimental system for comparing the physiological genetics of photoperiodism under uniform environmental conditions.

In addition to inducing growth cessation and bud set, SDs eventually induce endodormancy in both eastern and black cottonwood (Jian et al., 1997; G.T. Howe, unpublished results). Nonetheless, other changes, such as leaf senescence and abscission, are not induced by SDs alone, but require exposure to low temperatures $\left(\approx 5^{\circ} \mathrm{C}\right.$; T.H.H. Chen, unpublished results; G.T. Howe, unpublished results). Therefore, one set of endodormancy-related responses appears to be induced by SDs, and another set by low temperatures. These low-temperature responses, however, may require prior exposure to SDs. Analogous results are observed for SD-induced cold acclimation. In a number of

Table 1. Geographic origins of eastern cottonwood (Populus deltoides) genotypes.

\begin{tabular}{lcc}
\hline Clone & State & Latitude $\left({ }^{\circ} \mathrm{N}\right)$ \\
\hline S7C4 & Texas & $30^{\circ} 30^{\prime}$ \\
108 & Oklahoma & $33^{\circ} 30^{\prime}$ \\
117 & Oklahoma & $33^{\circ} 50^{\prime}$ \\
118 & Oklahoma & $33^{\circ} 50^{\prime}$ \\
$251-3$ & Missouri & $38^{\circ} 5^{\prime}$ \\
$235-2$ & Missouri & $38^{\circ} 50^{\prime}$ \\
$217-3$ & Ohio & $38^{\circ} 55^{\prime}$ \\
$243-1$ & Missouri & $39^{\circ} 00^{\prime}$ \\
$52-2$ & Ohio & $40^{\circ} 30^{\prime}$ \\
$273-1$ & Illinois & $41^{\circ} 45^{\prime}$ \\
$286-1$ & Illinois & $41^{\circ} 55^{\prime}$ \\
$284-3$ & Illinois & $41^{\circ} 55^{\prime}$ \\
$172-2$ & Minnesota & $44^{\circ} 20^{\prime}$ \\
$172-4$ & Minnesota & $44^{\circ} 20^{\prime}$ \\
\hline
\end{tabular}

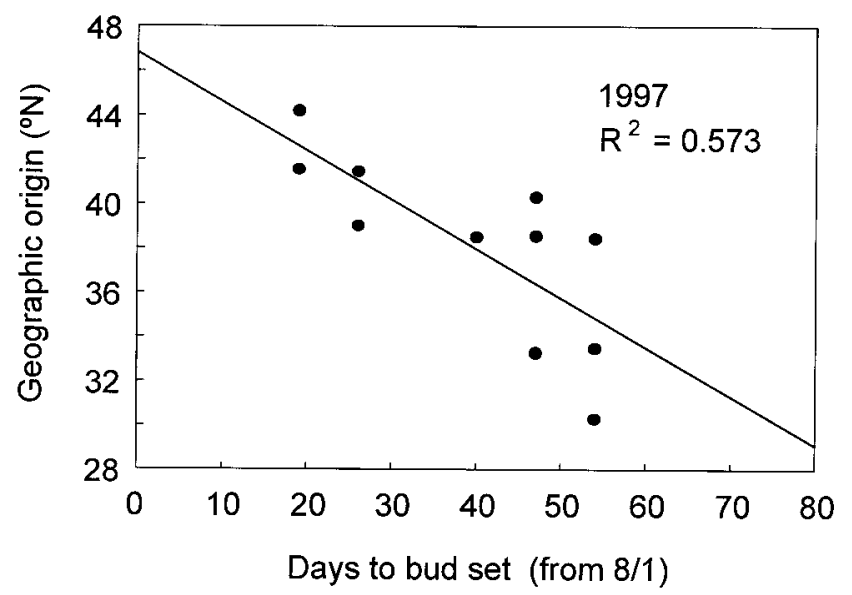

Fig. 3. The relationship between latitudinal origin and the timing of terminal bud set for eastern cottonwood (Populus deltoides) trees growing in the field in Corvallis, Ore. 
species, a modest degree of cold hardiness is induced by SDs alone, but a second stage of acclimation, which leads to significant increases in cold hardiness, is induced by subsequent exposure to low temperatures (reviewed in Fuchigami et al., 1971b).

We also investigated ecotypic variation in eastern cottonwood growing under natural conditions. Genotypes from a range of latitudinal origins (Table 1) were grown in Corvallis, Ore. $\left(44^{\circ} 34^{\prime} \mathrm{N}\right)$, and the timing of bud set was recorded. The number of days to bud set was negatively correlated with latitudinal origin, demonstrating that pronounced ecotypic variation can be detected for this species under natural conditions (Fig. 3) (Pauley and Perry, 1954). The ecotypic variation that is present in both eastern and black cottonwood provides us with useful systems for studying genetic variation in a host of endodormancy-related traits.

We characterized endodormancy induction and release in eastern cottonwood (clone 172-2) by growing trees under natural conditions, and under SDs in a controlled environment (8-h day/16-h night) (Fig. 4). On each sampling date, trees from each environment were moved to LD conditions (16-h day/8-h night) in the greenhouse to determine the degree of endodormancy. After these trees were manually defoliated and the apical buds were removed, the degree of endodormancy was measured as the number of days to axillary bud flush. After 10 weeks, the trees growing under SDs were transferred to a cold room to fulfill their chilling requirement, and endodormancy was measured every 2 weeks thereafter. Although the trees growing under SDs formed a terminal bud in $\approx 3$ weeks, there was no change in endodormancy during this time. There was a slight change in endodormancy by week 5 , and after 6 weeks, endodormancy increased rapidly. After 10 weeks of SDs, the trees required $>250 \mathrm{~d}$ to break bud under LD conditions. At this time, the trees were transferred to a cold room. After 10 weeks of chilling (i.e., by week 20), the endodormancy of these trees had declined significantly, almost to the level of the controls growing under LDs ( $<20 \mathrm{~d}$ to bud flush). Thus, we can reproduce the annual endodormancy cycle in $\approx 20$ weeks, and can complete almost three endodormancy cycles per year. Under natural conditions, the degree of endodormancy varies among years because of temperature fluctuations and variability in other environmental factors. Because we can use daylength and temperature treatments to induce and release endodormancy in controlled environments, this system is both reproducible and reliable.

We used this system to investigate changes in apical bud ultrastructure in eastern cottonwood (Jian et al., 1997). As endodormancy increased, we observed increases in the thickness of cell walls, in the number of starch granules, and in storage proteins in the vacuoles of the apical bud cells. The most striking change was the constriction and blockage of the plasmodesmata. Cell division in the apical cells

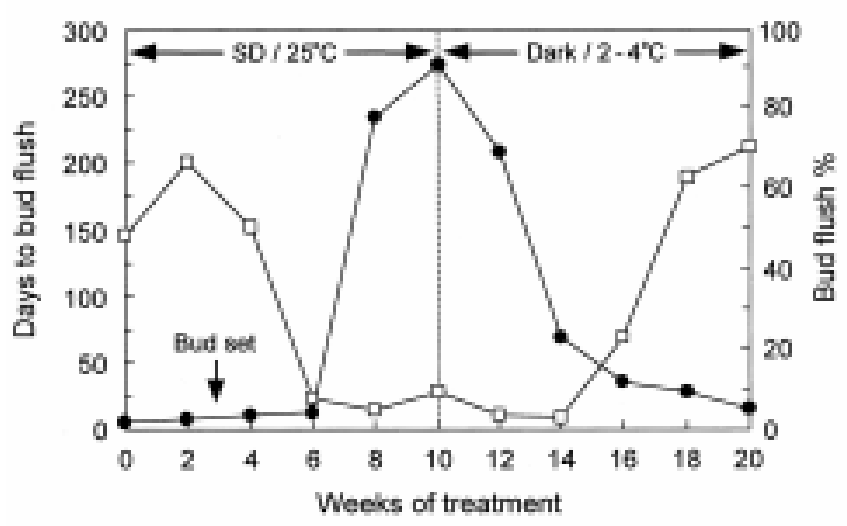

Fig. 4. Degree of endodormancy of eastern cottonwood trees (Populus deltoides clone 172-2) sampled bi-weekly from controlled environments. Degree of endodormancy was measured as both the number of days to bud flush ( - - ) and percentage bud flush ( $\square-$ ) on decapitated and defoliated trees as described in the text. seemed to be completely arrested after 2 to 3 weeks of SDs. The constriction and blockage of plasmodesmata may cause discontinuities in symplastic transport and may limit cellular communication and signal transduction between adjacent cells. This, in turn, may lead to events associated with growth cessation and bud endodormancy. The potential roles of plasmodesmata in bud endodormancy were recently reviewed by van der Schoot (1996).

We also investigated calcium distribution within the apical bud during the induction of endodormancy (Jian et al., 1997). Calcium antimonate precipitates form when apical buds are fixed with potassium antimonate. Under LDs, calcium precipitates were found mainly in the vacuoles, intercellular spaces, and plastids. Some $\mathrm{Ca}^{2+}$ deposits were also found in the cell walls and at the orifice of the plasmodesmata, but there were few $\mathrm{Ca}^{2+}$ deposits in either the cytosol or nucleus. After exposure to $20 \mathrm{SDs}$, when cell division had stopped and the plants were beginning to become endodormant, fewer $\mathrm{Ca}^{2+}$ deposits occurred in the intercellular spaces, and deposits were now found in both the cytosol and nucleus. A large number of $\mathrm{Ca}^{2+}$ deposits remained in the cytosol and nucleus between days 28 and 49 of SD exposure. When deep endodormancy was reached after $77 \mathrm{~d}$ of SD exposure, $\mathrm{Ca}^{2+}$ deposits were less pronounced in both the cytosol and nucleus, whereas numerous deposits were again observed in the cell walls and intercellular spaces. These results indicate that changes in subcellular $\mathrm{Ca}^{2+}$ localization and apical bud ultrastructure occur during the induction of endodormancy. Alterations in $\mathrm{Ca}^{2+}$ levels regulate many cellular processes in plants, including ion transport and gene expression (Bush, 1995). In addition, environmental stimuli such as temperature and light can alter cellular $\mathrm{Ca}^{2+}$ distribution (Bush, 1995). Our results suggest that calcium may be an important regulator of SDinduced endodormancy.

\section{Analyses of differential gene expression}

Biochemical changes are associated with bud endodormancy in woody plants, including changes in enzymatic activity and nucleic acid synthesis (Häggman et al., 1985; Li et al., 1989; Nir et al., 1986; Wang et al., 1991). Significantly, Zimmerman and Faust (1969) observed substantial incorporation of uracil and valine into the nucleic acid and protein fractions of pear (Pyrus calleryana Dcne.) buds during the winter, indicating that RNA and protein metabolism are occurring in endodormant buds. These results suggest that changes in gene expression are important during dormancy induction, maintenance, and release.

Analyses of differential gene expression are essentially physiological approaches that seek to identify genes whose patterns of expression are closely associated with the trait of interest. Differences in gene expression are usually evaluated by measuring differences in the steady-state levels of either proteins or mRNAs within tissues, organs, or whole plants. Direct evidence for dormancy-associated changes in gene expression was obtained by in vitro translation of poly(A)+ RNA isolated from dormant buds of Scots pine (Pinus sylvestris L.) (Nuotio et al., 1990). In imbibed seeds of oat (Avena fatua L.) and wheat (Triticum aestivum L.), the levels of individual polypeptides and/or mRNAs differ between dormant and nondormant embryos (Dyer, 1993; Li and Foley, 1994; Reid and Walker-Simmons, 1990). The cDNAs corresponding to differentially expressed genes were isolated using differential screening ( $\mathrm{Li}$ and Foley, 1995) and differential display (Johnson et al., 1995). Sequence analyses of these cDNAs suggest that some of the differentially expressed genes encode late embryogenesis-abundant (LEA) proteins, aldose reductase, and glutathione peroxidase, whereas others have no significant similarities to any known genes (Johnson et al., 1995; Li and Foley, 1995). Overall, these observations suggest that differential gene expression probably plays an important role in both seed and bud dormancy.

\section{Differential expression at the protein level}

Techniques based on sodium dodecyl sulfate polyacrylamide gel electrophoresis (SDS-PAGE) are commonly used to examine differential gene expression at the protein level. In one-dimensional SDSPAGE, proteins are isolated from the tissue of interest, dissociated into 
individual polypeptide subunits using SDS, and the resulting SDSpolypeptide complexes are separated on a polyacrylamide gel. Using this technique, one can determine the relative abundance of polypeptides that differ in mass. Using one-dimensional SDS-PAGE, two classes of highly abundant proteins have been discovered that are associated with endodormancy in a wide array of woody plants. These are the vegetative storage proteins and the dehydrins (reviewed in Rowland and Arora, 1997). We will discuss one class of vegetative storage proteins, the bark storage proteins, as an example of how analyses of differential expression at the protein level can lead to important insights about endodormancy-related processes.

Bark storage proteins (BSPs). A class of vegetative storage proteins (VSPs) that accumulate mostly in bark tissue and are, therefore, called bark storage proteins (BSPs) has been studied in Populus (reviewed in Coleman, 1997). The BSPs belong to a larger group of VSPs that function as important nitrogen reserves in many plant species (reviewed in Stepien et al., 1994). In deciduous trees, leaf proteins are hydrolyzed in the autumn and the amino acids are translocated to perennial organs where they are incorporated into VSPs (Coleman, 1997; Stepien et al., 1994; Titus and Kang, 1982). During the fall and winter, VSPs accumulate in the bark and wood of both stems and roots (Stepien et al., 1994). In the spring, the VSPs are broken down and their products are translocated to the sites of active spring growth (Coleman, 1997; Stepien et al., 1994; Titus and Kang, 1982).

A temporal association between BSP accumulation and endodormancy was discovered by analyzing seasonal changes in protein levels using one-dimensional SDS-PAGE and other techniques (Nsimba-Lubaki and Peumans, 1986; O'Kennedy and Titus, 1979; van Cleve et al., 1988; Wetzel et al., 1989). In poplar stem tissues, for example, proteins of 32, 36, and/or $38 \mathrm{kDa}$ were found to accumulate in the fall and decline in the spring (Langheinrich and Tischner, 1991; Stepien and Martin, 1992; van Cleve et al., 1988). Therefore, the accumulation and decline of BSPs is correlated with endodormancy induction and release. Detailed analyses of these proteins in hybrid poplar suggest that the 32,36 , and $38 \mathrm{kDa}$ proteins are glycosylated isoforms of the same polypeptide, and that native BSP occurs as a heterodimer of two isoforms (Langheinrich and Tischner, 1991; Stepien and Martin, 1992; Stepien et al., 1992). BSPs are also associated with endodormancy for another reason; both BSP accumulation and endodormancy are induced by SDs (Coleman et al., 1991, 1992). Despite these associations, there is no good evidence that BSPs play a direct role in endodormancy per se (Coleman et al., 1993, 1994).

Purified poplar BSPs were used to produce antibodies, and the resulting BSP antisera were used for isolating the corresponding genes (Clausen and Apel, 1991; Coleman et al., 1992). For example, both cDNA and genomic clones corresponding to the $32 \mathrm{kDa}$ BSP from eastern cottonwood were isolated and sequenced, and the associated gene was designated bspa (Coleman and Chen, 1993; Coleman et al., 1992). Analyses of gene expression indicated that BSP accumulation is influenced by daylength, temperature, nitrogen availability, and wounding, and that there is an interaction between these factors (Coleman et al., 1991, 1992, 1994; Davis et al., 1993; Langheinrich and Tischner, 1991; Stepien and Sauter, 1994; van Cleve and Apel, 1993). For example, SD-induced BSP accumulation is delayed in plants that are provided with low levels of nitrogen (Bañados, 1992; Coleman et al., 1994). Conversely, BSP accumulation can be induced under LDs by providing excess nitrogen (Coleman et al., 1994). Results from nuclear runoff transcription assays and promoter analyses indicate that the effects of SDs and nitrogen on BSP accumulation involve different mechanisms (G.D. Coleman and T.H.H. Chen, unpublished results). Therefore, BSP may be regulated at both the transcriptional and translational levels. The induction of BSP accumulation by SDs and nitrogen is tissue-specific; BSP and BSP mRNA are mainly detected in the bark tissues of the stem, and in lateral and terminal buds (Bañados, 1992; Coleman et al., 1994).

Results from Southern blot analyses indicate that BSPs are encoded by a small, clustered, multigene family in poplars (Coleman et al., 1992; Davis et al., 1993). Although poplars have been particularly important for studying BSPs in woody plants, BSPs have been found in a diverse array of angiosperm and coniferous species (Coleman,
1997). Whether BSPs have any direct role in bud endodormancy is still unclear.

Dormancy-related changes in gene expression have also been detected using two-dimensional SDS-PAGE. In pea (Pisum sativum L.), for example, lateral buds remain paradormant until they are stimulated to develop by decapitating the stem. Stafstrom and Sussex (1988) compared the protein patterns of lateral buds collected from intact plants with those collected from plants after decapitation. They demonstrated that unique sets of proteins were expressed in the nondormant and paradormant buds. One drawback to analyses of gene expression at the protein level is the relative difficulty of identifying the genes that encode the differentially expressed proteins. Devitt and Stafstrom (1995), for example, subsequently used both differential screening and candidate gene approaches (discussed below) to identify genes that were up-regulated in the nondormant pea buds. These paradormancy-related genes encode histones, ribosomal proteins, MAP kinase, cdc2 kinase, and cyclin B (Devitt and Stafstrom, 1995; Stafstrom and Sussex, 1992; Stafstrom et al., 1993).

Analyses of protein profiles of endodormant poplar buds. We analyzed the protein profiles of terminal and lateral buds of eastern cottonwood during endodormancy development (10 weeks of SDs) using two-dimensional SDS-PAGE (Jeknić and Chen, 1999). The majority of the polypeptides present in the LD controls were also present in the trees grown under SDs. Nonetheless, SD treatment resulted in the appearance of new polypeptides and the down-regulation of other polypeptides (Table 2). In terminal buds, for example, eight polypeptides appeared or increased in abundance, whereas 11 polypeptides disappeared by week 10 . The SD-induced changes in polypeptides that occurred in lateral buds were similar to those found in terminal buds. In lateral buds, six polypeptides appeared or increased in abundance by week 6 , whereas eight polypeptides disappeared during the 10-week experiment. Four of the eight polypeptides that appeared in terminal buds seem to be identical to those that also appeared in lateral buds. Similarly, five of the 10 polypeptides that disappeared in terminal buds seem to be identical to those that also disappeared in lateral buds.

Because the SD treatment resulted in the appearance of new polypeptides and the disappearance of others, specific changes in gene expression appear to be associated with the induction of endodormancy. The next step will be to identify these polypeptides and their corresponding genes. In particular, we will focus on those polypeptides that either appeared or disappeared in both terminal and lateral buds during SD treatment. The identification and molecular characterization of these polypeptides should contribute to a better understanding of the molecular mechanisms controlling endodormancy induction, maintenance, and release.

Although changes in proteins may be more biologically meaningful than changes in mRNAs, protein-based methods are not sensitive enough to detect genes that are expressed at very low levels, and are not suitable for easily identifying the differentially expressed proteins. For these reasons, analyses of differential gene expression at the RNA level are important adjuncts or alternatives to the analyses described above.

\section{Differential expression at the RNA level}

Analyses of differential expression at the RNA level have some advantages over analyses at the protein level. For example, most RNAbased techniques facilitate the identification and cloning of genes that are differentially expressed and permit the detection of genes that are expressed at very low levels. Approaches that have been used to study

Table 2. Number of proteins (polypeptides) that either appeared (+) or disappeared (-) in poplar buds during 10 weeks of short-day (SD) treatment.

\begin{tabular}{|c|c|c|c|c|c|c|c|c|c|c|c|c|}
\hline \multirow{3}{*}{$\begin{array}{l}\text { Bud } \\
\text { position }\end{array}$} & \multicolumn{10}{|c|}{ SD treatment (weeks) } & \multirow{2}{*}{\multicolumn{2}{|c|}{ Total }} \\
\hline & \multicolumn{2}{|c|}{2} & \multicolumn{2}{|c|}{4} & \multicolumn{2}{|c|}{6} & \multicolumn{2}{|c|}{8} & \multicolumn{2}{|c|}{10} & & \\
\hline & + & - & + & - & + & - & + & - & + & - & + & - \\
\hline 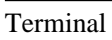 & 2 & 4 & 3 & 1 & 4 & 3 & 2 & 2 & 0 & 1 & 8 & 11 \\
\hline Lateral & 3 & 2 & 1 & 1 & 2 & 3 & 0 & 1 & 0 & 1 & 6 & 8 \\
\hline
\end{tabular}


endodormancy-related genes include in vitro translation, differential screening, differential display, and analyses of cDNA amplified restriction fragment polymorphisms (cDNA-AFLPs). In vitro translation, for example, was used to identify genes that were differentially expressed in Scots pine buds during the winter (Nuotio et al., 1990). Based on differences in the polypeptide patterns between buds collected in January and February, gene expression appeared to change during periods of very low temperatures (Nuotio et al., 1990). With the advent of more powerful techniques, however, in vitro translation is no longer widely used for analyses of differential gene expression.

Differential screening. In most differential screening protocols, a cDNA library is screened using two probes representing mRNA populations from two tissues that differ in the trait of interest. For example, cDNA libraries constructed from dormant embryos of rye brome (Bromus secalinus L.) and wild oat (Avena fatua L.) were screened using probes representing mRNAs from dormant and nondormant embryos (Goldmark et al., 1992; Li and Foley, 1995). By comparing the levels of plaque hybridization using these two different probes, cDNAs encoding genes that were preferentially expressed in dormant embryos were identified (Goldmark et al., 1992; Li and Foley, 1995). There are many variants to this basic approach, including the screening of a single (e.g., dormant) cDNA library (Goldmark et al., 1992; Li and Foley, 1995), or the screening of cDNA libraries from each tissue of interest (e.g., dormant and nondormant). This latter approach would facilitate the detection of both up-regulated and down-regulated genes in dormant tissues. In other cases, the libraries or probes may be derived from differentially expressed mRNAs. Li and Foley (1995), for example, screened a "subtracted" cDNA library that was enriched for genes preferentially expressed in dormant embryos. Compared with protein-based methods and in vitro translation, the main advantages of differential screening (and the other RNA-based techniques discussed below) are that they facilitate the identification and cloning of the differentially expressed genes and the detection of genes that are expressed at relatively low levels.

In the examples cited above, the genes that were up-regulated in dormant embryos appear to encode LEA proteins, aldose reductase, and other unidentified proteins (Goldmark et al., 1992; Li and Foley, 1995). In addition, genes that were up-regulated in dormant embryos were also up-regulated by ABA in nondormant embryos (Goldmark et al., 1992; Li and Foley, 1995).

Differential display and analyses of cDNA-AFLPs. Differential display and cDNA-AFLPs are related PCR-based techniques that can be used to identify differentially expressed mRNAs (T.H.H. Chen, unpublished data; Johnson et al., 1995). In both techniques, the differentially expressed messages can be cloned and identified relatively easily. Compared with differential screening, differential display and cDNA-AFLPs are less biased against rare messages, have a lower requirement for starting material (because of the PCR amplification step), and are relatively simple (Johnson et al., 1995). The main disadvantages are that differences in gene expression at the protein level will not be detected, there is often a large number of false positives, and important genes could be missed because only a subset of the genes are amplified in each reaction (Johnson et al., 1995).

Differential display was used to identify and clone cDNAs for several genes that are differentially expressed in dormant and nondormant oat embryos (Johnson et al., 1995). Five genes were cloned, two that were preferentially expressed in dormant embryos, and three that were preferentially expressed in nondormant embryos. One of these latter genes may encode a glutathione peroxidase (Johnson et al., 1995).

Using the cDNA-AFLP procedure, we identified and cloned several differentially expressed genes from terminal buds of eastern cottonwood trees growing under SDs. The AFLP-cDNA fragments were generated using PCR, then visualized on polyacrylamide gels. The fragments that appeared to correspond to differentially expressed genes were re-amplified and cloned into plasmids. To verify the differential expression of the cloned genes, they were hybridized to slot blots containing total RNA isolated from buds that had been collected after $0,1,2,4,6$, and 8 weeks of exposure to SDs.

Using these procedures, we detected 20 to $50 \mathrm{cDNA}$-AFLP bands per primer combination, many of which appeared to represent differ-

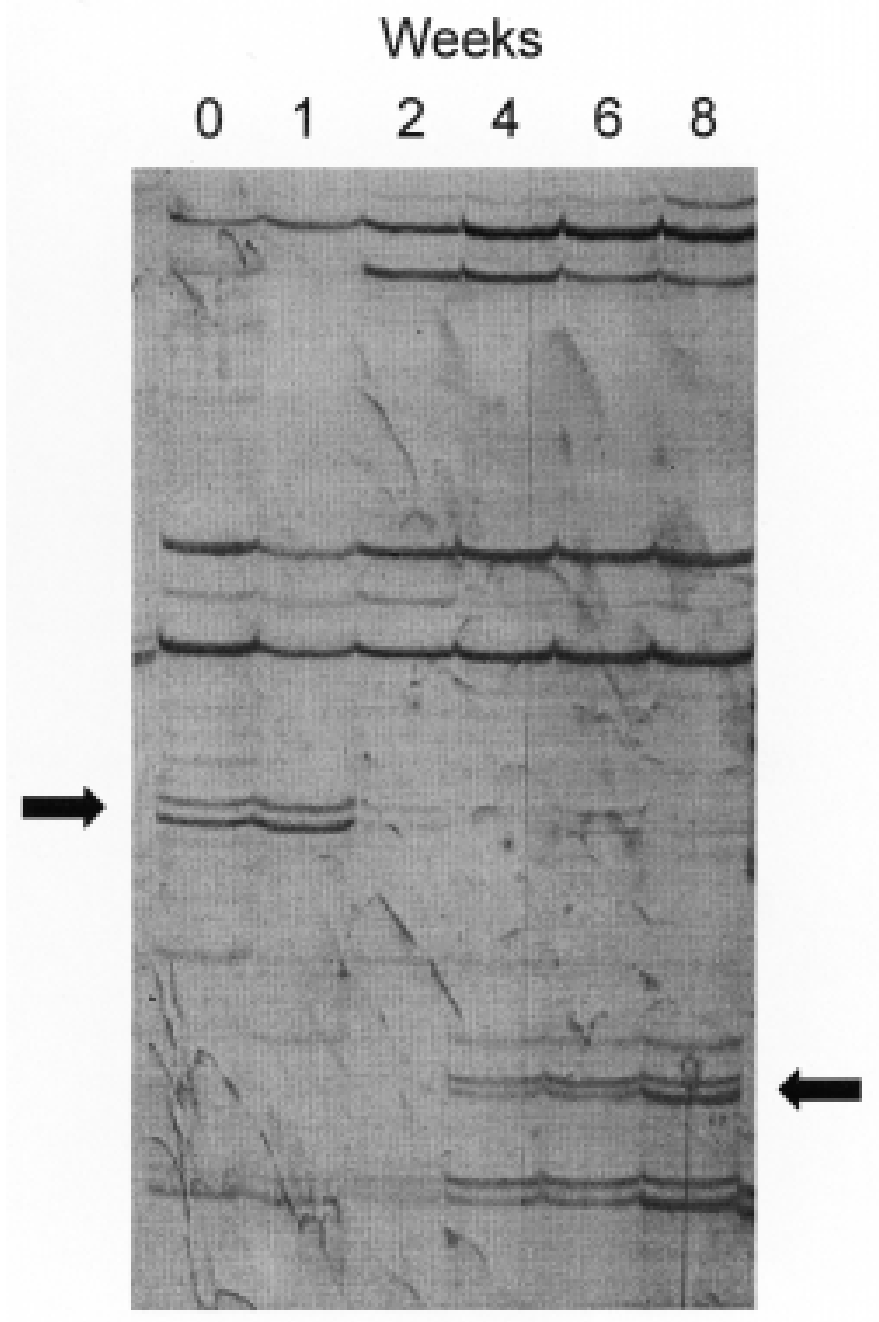

Fig. 5. cDNA-AFLP fragments synthesized from eastern cottonwood trees (Populus deltoides clone 172-2) growing under SD conditions (8-h day/16h night) for 0 to 8 weeks. cDNA-AFLPs were generated using the PerkinElmer AFLP Plant Mapping Kit according to the protocol provided by the manufacturer (Perkin-Elmer Corp., Norwalk, Conn.). Selectively amplified cDNA-AFLP fragments were subjected to electrophoresis on $6 \%$ polyacrylamide denaturing gels, stained with silver, then air-dried overnight. Arrows indicate cDNA fragments that appear to correspond to differentially expressed mRNAs.

entially expressed genes. Some fragments appeared only after 4 weeks of SD treatment, whereas others appeared shortly after the SD treatments were initiated, but later disappeared (Fig. 5). From the first 32 primer combinations, 76 cDNA-AFLP bands were chosen for reamplification because they appeared to represent differentially expressed genes. Sixty-four of these were successfully re-amplified and are currently being studied. To date, 24 of these cDNAs have been cloned and sequenced, 11 have been checked for similarity to sequences in the GenBank and EMBL databases (Table 3), and four were used to probe the RNA slot blots. Although signals were not detected for two of these four clones, the other two appeared to be differentially expressed (Fig. 6). We are continuing to generate additional cDNA fragments for cloning and sequencing, and expect to have $\approx 100$ differentially expressed cDNA clones for study.

\section{Genetic approaches}

Genetic approaches are those aimed at identifying endodormancyrelated genes by comparing the inheritance patterns of endodormancy- 
Table 3. Sequence analyses of cDNA-AFLP clones.

\begin{tabular}{|c|c|c|c|c|}
\hline \multirow[b]{2}{*}{ Clone } & \multirow[b]{2}{*}{$\begin{array}{l}\text { Size } \\
(\mathrm{bp})\end{array}$} & \multicolumn{3}{|c|}{ Best match ${ }^{1}$} \\
\hline & & $\begin{array}{l}\text { Match } \\
\text { (bp/bp) }\end{array}$ & Species or hybrid & Putative gene product or genomic sequence ${ }^{2}$ \\
\hline$\overline{\mathrm{A} 1-7}$ & 128 & $101 / 114$ & Populus tremula L. x P. tremuloides Michx. & Cytosolic phosphoglucomutase (AF097938) \\
\hline A2-2 & 203 & $33 / 44$ & Arabidopsis thaliana (L.) Heynh. & Genomic sequence from BAC clone F26F24 (AC005292) \\
\hline A2-4 & 200 & $42 / 50$ & Arabidopsis thaliana & ATAF1 mRNA (X74755) \\
\hline A3-1 & 237 & $68 / 108$ & Phaseolus vulgaris L. & Peroxidase 5 precursor (AF149280) \\
\hline A3-3 & 210 & $30 / 37$ & Saccharomyces cerevisiae Meyen & Subunit of cAMP-dependent protein kinase (X05051) \\
\hline B1-3 & 371 & $37 / 49$ & S. cerevisiae & $\begin{array}{l}\text { Bifunctional anthranilate synthase:indole- } 3 \\
\text { glycerol phosphate synthase }\end{array}$ \\
\hline B3-3 & 358 & $128 / 170$ & A. thaliana & Genomic sequence from BAC clone F9L1 (AC007951) \\
\hline B3-5 & 304 & $154 / 221$ & Sinapis alba $\mathrm{L}$. & Small subunit of ribulose bisphosphate carboxylase (X16435) \\
\hline B4-3 & 390 & $130 / 177$ & A. thaliana & Genomic sequence from BAC clone F18F4 (AL021637) \\
\hline B6-4 & 364 & $29 / 34$ & Williopsis saturnus (Klöcker) Zender var. saturnus & Killer toxin (D13446) \\
\hline C1-5 & 267 & $119 / 157$ & A. thaliana & Genomic sequence from PAC clone MRG7 (AB012246) \\
\hline
\end{tabular}

${ }^{1}$ Best matches were determined in June 1999 using the Basic Local Alignment Search Tool (BLAST).

${ }^{2}$ From the GenBank Definition field. Designations in parentheses are GenBank Accession numbers, BAC denotes bacterial artificial chromosome, PAC denotes P1 artificial chromosome.

related traits with the inheritance patterns of specific chromosomal regions defined by molecular markers (i.e., cosegregation analyses). Genetic approaches include classic Mendelian genetic analyses and analyses of quantitative trait loci. Because genetic approaches are fundamentally different from the physiological approaches described above, they are useful alternatives for detecting and identifying endodormancy-related genes. Genetic approaches can also be used to test whether specific candidate genes (including those identified using the physiological approaches described above) are associated with endodormancy-related traits.

\section{Mendelian genetic analyses}

If the trait of interest varies in a qualitative fashion, simple Mendelian genetic analyses may be useful for detecting endodormancyrelated genes. Mendelian genetic analyses were used, for example, to infer that "nondormant" genotypes of both peach [Prunus persica (L.) Batsch] and hazelnut (Corylus avellana L.) result from mutations in single genes (Rodriguez et al., 1994; Thompson et al., 1985). Chilling requirement was inherited in a semi-qualitative fashion in both openpollinated and control-cross progeny of the apple (Malus $\times$ domestica Borkh.) cultivar Anna (Hauagge and Cummins, 1991). Therefore, the low chilling requirement of this cultivar appears to be controlled by at least one major dominant gene. Dominance of low chilling requirement has also been observed in other apple crosses (Oppenheimer and Slor, 1968). Ultimately, it may be possible to identify these major genes by determining which specific loci cosegregate with the mutant phenotypes.

In contrast to the examples cited above, most endodormancyrelated traits appear to vary in a quantitative manner. Results from

\section{Weeks}
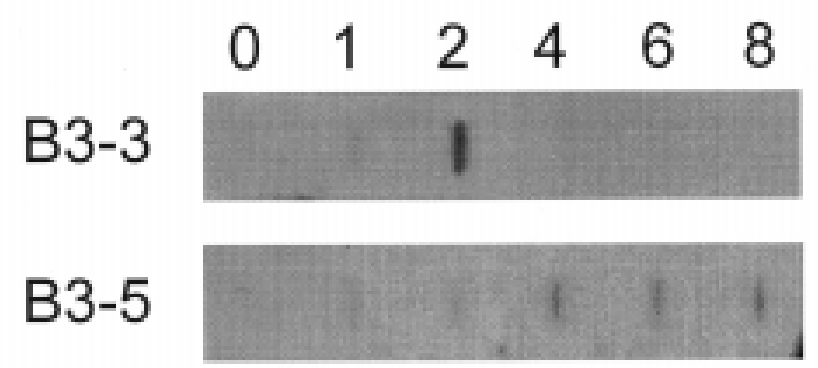

Fig. 6. Slot blots showing differential expression of two cDNA-AFLP clones isolated from eastern cottonwood trees (Populus deltoides clone 172-2). Total RNAs isolated from buds which had been collected after 0 to 8 weeks of exposure to SDs (8-h day/16-h night) were blotted, then hybridized to one of two cDNA-AFLP clones (B3-3 or B3-5). progeny tests indicate that phenotypes for a number of endodormancyrelated traits exhibit continuous distributions, presumably resulting from multigenic control plus environmental effects (Aitken and Adams, 1995; Billington and Pelham, 1991; Ekberg et al., 1985; Farmer and Reinholt, 1986). Results from controlled breeding experiments also suggest that endodormancy-related traits are influenced by multiple genes (Eriksson et al., 1978; Pauley and Perry, 1954). For traits that exhibit quantitative variation, Mendelian genetic analyses might be possible by first generating mutants (i.e., by creating new qualitative genetic variation). Although this approach is commonly used in model plants such as Arabidopsis, it is impractical for most tree species because they are difficult to self (due to substantial inbreeding depression or dioecy) and have generation times of 5 to 40 years (Kramer and Kozlowski, 1979).

\section{QTL analyses}

If Mendelian genetic analyses are not possible using either existing genetic variation or mutants, QTL analyses can be used to dissect quantitative traits into their Mendelian components (Tanksley et al., 1989). A QTL is a locus or region of the chromosome that has a significant effect on a quantitatively inherited trait (Tanksley, 1993). The first step in QTL analysis usually involves the development of a genetic linkage map using DNA-based markers such as RFLPs, RAPDs, AFLPs, or microsatellites, followed by a search for those genetic markers that cosegregate with the trait of interest (Lander and Botstein, 1989). A number of different designs have been used to map QTLs in trees, including inbred-like $F_{2}$ and backcross pedigrees, $F_{1}$ pedigrees, and three-generation full-sib pedigrees (Williams, 1998). Simplified alternatives such as bulk segregant analysis or selective genotyping may also be useful for detecting QTLs (Liu, 1998).

Molecular markers have been used to detect endodormancy-related QTLs in trees. In apple, the timing of reproductive bud flush was associated with a single molecular marker, and the timing of vegetative bud flush was associated with two molecular markers and one morphological marker (Lawson et al., 1995). Because these traits were studied using simple cosegregation analyses, other important QTLs may have been missed. In Populus, growth and phenological traits were studied using a three-generation inbred-like pedigree derived from a cross between black cottonwood and eastern cottonwood (Bradshaw and Stettler, 1995). Based on measurements made at a single field site, five QTLs with major effects on the timing of spring bud flush were identified. A model that included information on all five QTLs accounted for $85 \%$ of the genetic variation. In addition, the heritability of clonal means was 0.98 , higher than that for any other trait. These results indicate that the timing of bud flush is controlled by a modest number of major genes, and that environmental variation is low.

We are currently mapping endodormancy-related QTLs in Populus using the same pedigree design, but with a larger number of environments and $\mathrm{F}_{2}$ progeny. Preliminary QTL analyses have been conducted using as many as $337 \mathrm{~F}_{2}$ progeny and 278 AFLP and microsatellite 
markers. These markers are distributed among 26 maternal and 24 paternal linkage groups, and cover $68 \%$ to $77 \%$ of the estimated 2600 cM length of the Populus genome. Because poplars can be vegetatively propagated, these experiments include clonally replicated field plantations in both Oregon and Minnesota, as well as replicated experiments in controlled environments. In Oregon, we measured fall bud set and spring bud flush, whereas in Minnesota, we measured fall bud set, fall frost damage, and winter survival.

Preliminary quantitative genetic analyses indicate that bud set and bud flush are highly variable and under strong genetic control. Based on combined analyses of bud set in Oregon and Minnesota, for example, mean bud set dates ranged from 27 Aug. to 23 Nov., with a clonal mean heritability of 0.81 . Because the genetic correlation between bud set in Oregon and Minnesota was 0.81, there appears to be a modest genotype $\times$ environmental interaction for this trait. These results indicate that mapping bud set QTLs that are applicable to multiple environments should be possible. Based on the Oregon data, mean bud flush dates ranged from 4 Mar. to $13 \mathrm{Apr}$., with a clonal mean heritability of 0.94. Comparable analyses of the timing of bud flush in Minnesota were not possible because many of the trees did not survive the harsh winters. The trees in Minnesota were severely damaged by frosts at the end of October and beginning of November. Therefore, we also obtained information on genetic differences in freeze damage. Some of the $\mathrm{F}_{2}$ genotypes were killed by these early fall frosts, whereas others exhibited no damage. The heritability of freeze damage was lower than the heritabilities of the other endodormancy-related traits. The genetic correlation between bud set in Oregon and freeze damage in Minnesota was moderately positive, suggesting that genotypes that set bud earlier in the season are more resistant to freeze damage.

The timing of SD-induced bud set was also measured in controlled environments under warm temperatures and an 8-h photoperiod. In the greenhouse, SD-induced bud set was highly variable among $\mathrm{F}_{2}$ progeny and under strong genetic control. The earliest $\mathrm{F}_{2}$ progeny set bud $16 \mathrm{~d}$ after the start of the 8-h photoperiod, whereas other progeny set bud nearly 2 months later. The heritability of clonal means was 0.80 . The genetic correlation between the timing of bud set under an 8-h photoperiod (warm temperatures) and the timing of bud set in Oregon and Minnesota was relatively modest $\left(r_{g}=0.60\right)$. This result suggests that environmental factors other than daylength significantly influence genetic differences in the timing of bud set in the field. By combining both field and controlled-environment experiments it may be possible to dissect a complex collection of QTLs that control bud set in the field into sets of QTLs that regulate the timing of bud set via distinct environmental signals.

Results from preliminary QTL analyses using information from the Oregon field experiments indicate that multiple QTLs with modest effects on both the timing of bud set and bud flush can be detected. We are currently testing whether endodormancy candidate genes $P H Y A$, $P H Y B 1, P H Y B 2, A B I 1 B, A B I 1 D$, and $A B I 3$ are located near any of these QTLs (discussed below); QTL and candidate gene analyses of other endodormancy-related traits are underway. Although quantitative genetic analyses and QTL mapping are continuing, the results cited above clearly indicate that endodormancy induction and release are under strong genetic control, and that mapping QTLs for endodormancy-related traits is possible using this hybrid poplar pedigree.

\section{CANDIDATE GENE APPROACHES}

\section{Candidate genes}

"Candidate gene" approaches may be useful for identifying endodormancy-related genes. A candidate gene is a gene thought to be involved in some endodormancy-related process based on the gene's probable function. For example, the phytochrome, gibberellin (GA), and ABA signaling pathways appear to be important regulators of endodormancy-related traits (reviewed in Rohde et al., 1999). Therefore, genes encoding biosynthetic enzymes, receptors, or other components of these pathways should be investigated.

Phytochrome genes $(P H Y)$ encode photoreceptors involved in a diverse array of light-mediated responses, and one or more of the phytochromes are known to control photoperiodic responses in Populus (Howe et al, 1996; Olsen et al, 1997b). Therefore, phytochrome genes are logical candidates for playing important roles in a number of endodormancy-related traits. In addition, there are reasons to suspect that variation in the early steps in the phytochrome signaling pathway(s) may contribute to genetic variation in photoperiodic responses. In redosier dogwood [Cornus sericea L. (= C. stolonifera Michx.)], for example, ecotypic differences in cold-hardiness are largely the result of differences in the timing of cold-acclimation; acclimation began early in a cold-hardy genotype from North Dakota, but was delayed in a less-hardy genotype from Seattle, Wash. (Fuchigami et al., 1971a). When these genotypes were grafted and acclimated under SDs and low temperatures, the leaves of the North Dakota genotype increased the cold-hardiness of the Washington genotype. These results suggest that signaling events that occur in the leaves (i.e., at the sites of photoperiodic perception) differ between these genotypes. In addition, naturally occurring mutations in peach and hazelnut trees inhibit their ability to respond to SDs, resulting in "nondormant" phenotypes (Rodriguez et al., 1994; Thompson et al., 1985). Taken together, these results suggest that genetic variation in photoperiodic responses is associated with variation in relatively few genes that control groups of endodormancy-related traits, rather than variation in a large number of individual response genes. Therefore, genes that encode the phytochromes and other members of the phytochrome signaling pathway(s) should be investigated to determine their roles in endodormancyrelated traits in general, and whether they contribute to genetic variation in photoperiodic responses in particular.

The phytochromes consist of dimers of two apoproteins, each of which is covalently attached to a tetrapyrrole chromophore (Furuya and Song, 1994). Genes (PHY) which encode these apoproteins exist as a small gene family in most plants, including black cottonwood (Howe et al., 1998; Mathews and Sharrock, 1997). Black cottonwood contains three phytochrome genes, PHYA, PHYB1, and PHYB2, but apparently lacks members of the $P H Y C / F$ and $P H Y E$ subfamilies found in other angiosperms (Howe et al., 1998). Based on overexpression in transgenic plants, oat $P H Y A$ is capable of affecting photoperiodic responses in hybrid aspen $(P$.tremula L.XP. tremuloides Michx.), including SD-induced growth cessation and cold acclimation (Olsen et al., 1997b). However, whether or not the endogenous aspen PHYA exerts substantial control over these traits remains unclear. Current experiments designed to inhibit endogenous PHYA expression using antisense techniques should shed light on this question (T. Moritz, personal communication). In contrast, results from other species implicate $P H Y B$ in the photoperiodic control of flowering and tuberization (Childs et al., 1997; Jackson et al., 1998). Analyses of the functional roles of poplar $P H Y B 1$ vs. $P H Y B 2$, however, may be difficult because the protein-coding regions of these genes are very closely related (Howe et al., 1998). Nonetheless, these genes differ substantially in their putative $5^{\prime}$ and $3^{\prime}$ untranslated regions (P. Sarul and G.T. Howe, unpublished results). Of course, both PHYA and PHYB may be important photoreceptors for controlling photoperiodic responses in trees. In fact, models for phytochrome control of flowering that include roles for multiple phytochromes have been proposed (Thomas, 1991).

Because poplars contain at least three $P H Y$, each can be considered a candidate gene for endodormancy-related traits. To evaluate the roles of these genes, two questions need to be answered. First, which $P H Y$ play important functional roles in photoperiodic responses in trees? Second, are these genes responsible for genetic variation in photoperiodic responses? Answers to these questions will probably come from physiological approaches, such as modification of $P H Y$ expression in transgenic plants, and genetic approaches, such as gene mapping and QTL analyses. Limited research on genetic variability among black cottonwood genotypes suggests that substantial variability exists for at least one of the two $P H Y B$, although no variability was detected for $P H Y A$ (Howe et al., 1998). In addition, sequence variation has been detected among black cottonwood genotypes in the putative $5^{\prime}$ untranslated leaders of both $P H Y B 1$ and $P H Y B 2$ (P. Sarul and G.T. Howe, unpublished results).

We are using polymorphisms between black and eastern cottonwood to map poplar $P H Y$ using a three-generation hybrid poplar 
pedigree (unpublished results). The map locations of these genes are being compared with the locations of QTLs affecting the timing of bud set in the field and SD-induced bud set under controlled conditions (discussed above).

The GAs are a large group of tetracyclic diterpenes that regulate diverse aspects of plant growth and development, including photoperiodic control of growth cessation in woody perennial plants (Olsen et al., 1995; 1997b). Genes encoding GA biosynthetic enzymes have been isolated from a number of plant species (reviewed in Hedden and Kamiya, 1997), and genes encoding three key enzymes are being studied in hybrid aspen (D. Mozley, M.E. Eriksson, and T. Moritz, personal communication).

A number of genes involved in ABA signaling have been identified in Arabidopsis (reviewed in Merlot and Giraudat, 1997). Mutations in the $A B I 1$ and $A B I 3$ genes, for example, confer insensitivity to ABA. $A B I 1$ encodes a protein phosphatase and $A B I 3$ encodes a transcription factor (Merlot and Giraudat, 1997). Analyses of the expression of $A B I 1$ and $A B I 3$ homologues in Populus suggest roles for these genes in bud endodormancy (reviewed in Rohde et al., 1999). Other potential candidate genes include those with secondary regulatory functions, such as cell cycle genes, and genes with direct (i.e., nonregulatory) roles in endodormancy-related adaptations, such as genes encoding bark storage proteins and dehydrins (Coleman 1997; Rohde et al., 1997; Rowland and Arora, 1997).

We are mapping $P H Y A, P H Y B 1, P H Y B 2, A B I 1 B, A B I 1 D$, and $A B I 3$ in the hybrid poplar pedigree described above. This information, plus the results from QTL analyses, will allow us to test the hypothesis that these candidate genes are major QTLs for endodormancy-related traits. Because auxin, cytokinins, and ethylene may also regulate dormancy-related traits in seeds and/or buds (Kępczynśsi and Kępczyńska, 1997; Moritz, 1995; Olsen et al., 1997a, 1997b), genes associated with these pathways may be important as well. Genes encoding components of signaling pathways are particularly interesting because they are potentially involved in coordinated regulation of multiple endodormancy-related traits.

\section{CONCLUSIONS AND PROSPECTS}

Species and hybrids of Populus are good models for studying the physiology and genetics of endodormancy-related traits in trees and other perennial plants. Physiological and genetic approaches are being used to identify "new" endodormancy-related genes in poplars, and to examine the roles of specific candidate genes in endodormancyrelated traits. A major challenge will be to develop information that contributes to the applied use of woody crops. Research aimed at identifying and characterizing endodormancy-related genes, for example, may contribute to the development of 1) better tree crops via conventional breeding or genetic engineering, 2) improved cultural practices for controlling endodormancy-related traits, and/or 3) additional tools for studying the physiological genetics of endodormancy.

Much of the research on poplars has focused on the induction of endodormancy in general, and the regulatory role of photoperiod, in particular. These topics are being addressed using a range of approaches, including analyses of differential gene expression, candidate gene evaluation, and QTL mapping. Research on both the maintenance and release of endodormancy, however, is lagging. In addition, we know little about how temperature affects endodormancyrelated traits at the molecular genetic level, yet temperature influences all aspects of endodormancy. Temperature interacts with daylength to control the timing of growth cessation and bud set (Downs and Bevington, 1981; Junttila, 1980), and a number of other endodormancyrelated traits are induced by low temperatures, rather than daylength alone. Although SDs induce bud set and endodormancy, poplar trees do not shed their leaves unless they are exposed to low, above-freezing temperatures (T.H.H. Chen unpublished data; G.T. Howe, unpublished data). In other species, near-freezing temperatures are needed to induce the so-called second stage of cold acclimation (reviewed in Fuchigami et al., 1971a). These responses, however, seem to require prior exposure to SDs.

Temperature is also the major environmental factor controlling endodormancy release via chilling, and the timing of bud flush after the chilling requirement has been satisfied. Although work on fruit trees has addressed the physiological genetics of chilling requirements and bud flush (reviewed in Rowland and Arora, 1997), more work is needed. The influence of temperature on endodormancy-related traits has often been viewed as occurring through "global," nonspecific processes. For example, low temperatures influence enzyme activities and membrane properties, which could influence a large number of endodormancy-related traits. Nonetheless, we should entertain the hypothesis that specific temperature signaling mechanisms exist. Analogies can be made between the effects of temperature on SDinduced growth cessation and the influence of day/night temperature differentials (DIFs) on internode elongation (Downs and Bevington, 1981; Jensen et al., 1996; Junttila, 1980). In addition, the influence of chilling on bud endodormancy may be analogous to effects of chilling and vernalization on seeds and seedlings of annual plants. These analogies may point to other approaches and candidate genes that should be investigated in relation to bud endodormancy. Vernalization-related genes, for example, have been detected in wheat (Triticum aestivum L.) and Arabidopsis thaliana (Chong et al., 1994; Clarke and Dean, 1994), and similar endodormancy-related genes may exist in trees.

In addition to daylength and temperature, other environmental signals such as drought and nutrient availability influence endodormancy-related traits (Junttila 1989; Perry 1971). Eventually, information on these factors should be integrated into an overall picture of endodormancy. Much of our discussion has focused on the environmental control of endodormancy because genes involved in these processes probably have substantial impacts on entire groups of endodormancy-related traits, and may be responsible for much of the genetic variation in these traits. Nonetheless, the individual "response" genes and processes that are directly responsible for the adaptations that allow plants to survive harsh winter conditions deserve attention. In contrast with the seasonally indeterminate growth exhibited by young poplar trees, older trees and trees of other species often stop growing in early summer and become dormant in response to unknown "endogenous" factors. A complete understanding of endodormancy will ultimately require that we understand the physiological genetics of this process, as well.

Finally, to merely describe endodormancy-related genes and processes in individual plants is insufficient. The physiological genetics of endodormancy-related traits must be studied at the population level. Genetic variation in endodormancy-related traits has had an enormous impact on plant micro- and macroevolution. In addition, an understanding of this genetic variation is important for designing breeding strategies and for evaluating the potential impact of global climate change. Unlike mobile animal species and annual plants, populations of long-lived perennial plants such as trees may have difficulty adapting to changing environments, particularly if these changes occur rapidly (on an evolutionary time scale). Therefore, information on the levels and distributions of genetic variation in endodormancyrelated traits will be important for predicting the long-term survival of natural populations of trees.

\section{Literature Cited}

Aitken, S.N. and W.T. Adams. 1995. Screening for cold hardiness in coastal Douglas-fir, p. 321-324. In: B.M. Potts, N.M.G. Borralho, J.B. Reid, R.N. Cromer, W.N. Tibbits, and C.A. Raymond (eds.). Eucalypt plantations: Improving fibre yield and quality. Proc. CRC/IUFRO Conf., Hobart, 1924 Feb., CRC for Temperate Hardwood For., Hobart, Australia

Arora, R., M.E. Wisniewski, and R. Scorza. 1992. Cold acclimation in genetically related (sibling) deciduous and evergreen peach [ Prunus persica (L.) Batsch]. I. Seasonal changes in cold hardiness and polypeptides of bark and xylem tissues. Plant Physiol. 99:1562-1568.

Bañados, M.P. 1992. Nitrogen and environmental factors affect bark storage protein gene expression in poplar. M.S. Thesis, Dept. of Horticulture, Oregon State Univ., Corvallis.

Billington, H.L. and J. Pelham. 1991. Genetic variation in the date of budburst in Scottish birch populations: Implications for climate change. Funct. Ecol. 5:403-409.

Bradshaw, H.D., Jr. and R.F. Stettler. 1993. Molecular genetics of growth and development in Populus. I. Triploidy in hybrid poplars. Theor. Appl. Genet. 86:301-307. 
Bradshaw, H.D., Jr., and R.F. Stettler. 1995. Molecular genetics of growth and development in Populus. IV. Mapping QTLs with large effects on growth, form, and phenology traits in a forest tree. Genetics 139:963-973.

Bradshaw, H.D., Jr., M. Villar, B.D. Watson, K.G. Otto, S. Stewart, and R.F. Stettler. 1994. Molecular genetics of growth and development in Populus. III. A genetic linkage map of a hybrid poplar composed of RFLP, STS, and RAPD markers. Theor. Appl. Genet. 89:167-178.

Bush, D.S. 1995. Calcium regulation in plant cells and its role in signaling. Annu. Rev. Plant Physiol. Plant Mol. Biol. 46:95-122.

Cathey, H.M. 1990. USDA plant hardiness zone map. U.S Dept. of Agriculture Agr. Res. Serv. Misc. Publ. No. 1475.

Charest, P.J., Y. Devantier, C. Jones, J.C. Sellmer, B.H. McCown, and D.D. Ellis. 1997. Direct gene transfer in poplar, p. 60-64. In: N.B. Klopfenstein, Y.W. Chun, S.-S. Kim, and M.R. Ahuja (eds.). Micropropagation, genetic engineering, and molecular biology of Populus. U.S. Dept. of Agriculture Forest Service Gen. Tech. Rpt. RM-GTR-297.

Childs, K.L., F.R. Miller, M.-M. Cordonnier-Pratt, L.H. Pratt, P.W. Morgan, and J.E. Mullet. 1997. The sorghum photoperiod sensitivity gene, $M a_{3}$, encodes a phytochrome B. Plant Physiol. 113:611-619.

Chong, K., L.-P. Wang, K.-H. Tan, H.-L. Huang, and H.-G. Liang. 1994. Molecular cloning and characterization of vernalization-related (ver) genes in winter wheat. Physiol. Plant. 92:511-515.

Clarke, J.H. and C. Dean 1994. Mapping FRI, a locus controlling flowering time and vernalization response in Arabidopsis thaliana. Mol. Gen. Genet. 242:81-89.

Clausen, S. and K. Apel. 1991. Seasonal changes in the concentration of the major storage protein and its mRNA in xylem ray cells of poplar trees. Plant Mol. Biol. 17:669-678.

Coleman, G.D. 1997. Seasonal vegetative storage proteins of poplar, p. 124130. In: N.B. Klopfenstein, Y.W. Chun, S.-S. Kim, and M.R. Ahuja (eds.). Micropropagation, genetic engineering, and molecular biology of Populus. U.S Dept. of Agriculture Forest Service Gen. Tech. Rpt. RM-GTR-297.

Coleman, G.D., M.P. Bañados, and T.H.H. Chen. 1994. Poplar bark storage protein and a related wound-induced gene are differentially induced by nitrogen. Plant Physiol. 106:211-215.

Coleman, G.D. and T.H.H. Chen. 1993. Sequence of a poplar bark storage protein gene. Plant Physiol. 102:1347-1348.

Coleman, G.D., T.H.H. Chen, S.G. Ernst, and L. Fuchigami. 1991. Photoperiod control of poplar bark storage protein accumulation. Plant Physiol. 96:686-692.

Coleman, G.D., T.H.H. Chen, and L.H. Fuchigami. 1992. Complementary DNA cloning of poplar bark storage protein and control of its expression by photoperiod. Plant Physiol. 98:687-693.

Coleman, G.D., J.M. Englert, T.H.H. Chen, and L.H. Fuchigami. 1993. Physiological and environmental requirements for poplar (Populus deltoides) bark storage protein degradation. Plant Physiol. 102:53-59.

Davis, J.M., E.E. Egelkrout, G.D. Coleman, T.H.H. Chen, B.E. Haissig, D.E. Riemenschneider, and M.P. Gordon. 1993. A family of wound-induced genes in Populus shares common features with genes encoding vegetative storage proteins. Plant Mol. Biol. 23:135-143.

Devitt, M.L. and J.P. Stafstrom. 1995. Cell cycle regulation during growthdormancy cycles in pea axillary buds. Plant Mol. Biol. 29:255-265.

Downs, R.J. and J.M. Bevington. 1981. Effect of temperature and photoperiod on growth and dormancy of Betula papyrifera. Amer. J. Bot. 68:795-800.

Dyer, W.E. 1993. Dormancy-associated embryonic mRNAs and proteins in imbibing Avena fatua caryopses. Physiol. Plant. 88:201-211.

Ekberg, I., G. Eriksson, and Y. Weng. 1985. Between- and within-population variation in growth rhythm and plant height in four Picea abies populations. Studia Forestalia Suecica No.167.

Eriksson, G., I. Ekberg, I. Dormling, and B. Matern. 1978. Inheritance of budset and bud-flushing in Picea abies (L.) Karst. Theor. Appl. Genet. 52:319.

Farmer, R.E., Jr. and R.W. Reinholt. 1986. Genetic variation in dormancy relations of balsam poplar along a latitudinal transect in northwestern Ontario. Silvae Genet. 35:38-42.

Faust, M., A. Erez, and L.J. Rowland. 1997. Bud dormancy in perennial fruit trees: physiological basis for dormancy induction, maintenance, and release. HortScience 32:623-629.

Fillatti, J.J., J. Sellmer, B. McCown, B. Haissig, and L. Comai. 1987. Agrobacterium mediated transformation and regeneration of Populus. Mol. Gen. Genet. 206:192-199.

Fuchigami, L.H., D.R. Evert, and C.J. Weiser. 1971a. A translocatable cold hardiness promoter. Plant Physiol. 47:164-167.

Fuchigami, L.H. and C.-C. Nee. 1987. Degree growth stage model and restbreaking mechanisms in temperate woody perennials. HortScience 22:836845.

Fuchigami, L.H., C.J. Weiser, and D.R. Evert. 1971b. Induction of cold acclimation in Cornus stolonifera Michx. Plant Physiol. 47:98-103.

Furuya, M. and P.-S. Song. 1994. Assembly and properties of holophytochrome, p. 105-140. In: R.E. Kendrick and G.H.M. Kronenberg (eds.). Photomorphogenesis in plants, $2^{\text {nd }}$ ed. Kluwer, The Netherlands.

Goldmark, P.J., J. Curry, C.F. Morris, and M.K. Walker-Simmons. 1992. Cloning and expression of an embryo-specific mRNA up-regulated in hydrated dormant seeds. Plant Mol. Biol. 19:433-441.

Häggman, H., A. Hohtola, and S. Kupila-Ahvenniemi. 1985. Variation in the polysome assembly and incorporation of $\left[{ }^{3} \mathrm{H}\right]$-uridine in the cells of pine buds during the cold season. Physiol. Plant. 65:409-417.

Hauagge, R. and J.N. Cummins. 1991. Genetics of length of dormancy period in Malus vegetative buds. J. Amer. Soc. Hort. Sci. 116:121-126.

Hedden, P. and Y. Kamiya. 1997. Gibberellin biosynthesis: Enzymes, genes and their regulation. Annu. Rev. Plant Physiol. Plant Mol. Biol. 48:431460.

Howe, G.T.,P.A. Bucciaglia, G.R. Furnier, W.P. Hackett, M.-M. CordonnierPratt, and G. Gardner. 1998. Evidence that the phytochrome gene family in black cottonwood has one PHYA locus and two $P H Y B$ loci but lacks members of the PHYC/F and PHYE subfamilies. Mol. Biol. Evol. 15:160175 .

Howe, G.T., G. Gardner, W.P. Hackett, and G.R. Furnier. 1996. Phytochrome control of short-day-induced bud set in black cottonwood. Physiol. Plant. 97:95-103.

Howe, G.T., W.P. Hackett, G.R. Furnier, and R.E. Klevorn. 1995. Photoperiodic responses of a northern and southern ecotype of black cottonwood. Physiol. Plant. 93:695-708.

Jackson, S.D., P. James, S. Prat, and B. Thomas. 1998. Phytochrome B affects the levels of a graft-transmissible signal involved in tuberization. Plant Physiol. 117:29-32.

Jeknic', Z. and T.H.H. Chen. 1999. Changes in protein profiles of poplar tissues during the induction of bud dormancy by short-day photoperiods. Plant Cell Physiol. 40:25-35.

Jensen, E., S. Eilertsen, A. Ernsten, O. Junttila, and R. Moe. 1996. Thermoperiodic control of stem elongation and endogenous gibberellins in Campanula isophylla. J. Plant Growth Regulat. 15:167-171.

Jian, L.-C., P.H. Li, L.-H. Sun, and T.H.H. Chen. 1997. Alterations in ultrastructure and subcellular localization of $\mathrm{Ca}^{2+}$ in poplar apical bud cells during the induction of dormancy. J. Expt. Bot. 48:1195-1207.

Johnson, R.R., H.J. Cranston, M.E. Chaverra, and W.E. Dyer. 1995. Characterization of cDNA clones for differentially expressed genes in embryos of dormant and nondormant Avena fatua L. caryopses. Plant Mol. Biol. 28:113-122.

Junttila, O. 1980. Effect of photoperiod and temperature on apical growth cessation in two ecotypes of Salix and Betula. Physiol. Plant. 48:347-352.

Junttila, O. 1989. Physiological responses to low temperature. Ann. Sci. For. 46(Suppl):604-613.

Kępczyński, J. and E. Kępczyńska. 1997. Ethylene in seed dormancy and germination. Physiol. Plant. 101:720-726.

Kramer, P.J. and T.T. Kozlowski. 1979. Physiology of woody plants. Academic, New York.

Lander, E.S. and D. Botstein. 1989. Mapping Mendelian factors underlying quantitative traits using RFLP linkage maps. Genetics 121:185-199.

Lang, G.A. 1987. Dormancy: A new universal terminology. HortScience 22:817-820

Lang, G.A. 1994. Dormancy-The missing links: Molecular studies and integration of regulatory plant and environmental interactions. HortScience 29:1255-1263.

Langheinrich, U. and R. Tischner. 1991. Vegetative storage proteins in poplar. Induction and characterization of a 32- and a 36-kilodalton polypeptide. Plant Physiol. 97:1017-1025.

Lawson, D.M., M. Hemmat, and N.F. Weeden. 1995. The use of molecular markers to analyze the inheritance of morphological and developmental traits in apple. J. Amer. Soc. Hort. Sci. 120:532-537.

Li, B. and M.E. Foley. 1994. Differential polypeptide patterns in imbibed dormant and after-ripened Avena fatua embryos. J. Expt. Bot. 45:275-279.

Li, B. and M.E. Foley. 1995. Cloning and characterization of differentially expressed genes in imbibed dormant and afterripened Avena fatua embryos. Plant Mol. Biol. 29:823-831.

Li, Q.-B., L.-H. Liu, and H.-G. Liang. 1989. Changes in ribosome population and in nucleic acids during breaking of dormancy and development of apple flower buds. Physiol. Plant. 77:531-536.

Liu, B.-H. 1998. Statistical genomics: linkage, mapping, and QTL analysis. CRC Press, Boca Raton, Fla.

Liu, Z. and G.R. Furnier. 1993. Inheritance and linkage of allozymes and RFLPs in trembling aspen. J. Hered. 84:419-424.

Mathews, S. and R.A. Sharrock. 1997. Phytochrome gene diversity. Plant Cell Environ. 20:666-671.

Merlot, S. and J. Giraudat. 1997. Genetic analysis of abscisic acid signal transduction. Plant Physiol. 114:751-757.

Moritz, T. 1995. Biological activity, identification and quantification of gibberellins in seedlings of Norway spruce (Picea abies) grown under different 
photoperiods. Physiol. Plant. 95:67-72.

Newcombe, G. and H.D. Bradshaw, Jr. 1996. Quantitative trait loci conferring resistance in hybrid poplar to Septoria populicola, the cause of leaf spot. Can. J. For. Res. 26:1943-1950.

Newcombe, G., H.D. Bradshaw, Jr., G.A. Chastagner, and R.F. Stettler. 1996 A major gene for resistance to Melampsora medusae f. sp. deltoidae in a hybrid poplar pedigree. Phytopathology 86:87-94.

Nir, G., Y. Shulman, L. Fanberstein, and S. Lavee. 1986. Changes in the activity of catalase (EC 1.11.1.6) in relation to the dormancy of grapevine (Vitis vinifera L.) buds. Plant Physiol. 81:1140-1142.

Nsimba-Lubaki, M. and W.J. Peumans. 1986. Seasonal fluctuations of lectins in barks of elderberry (Sambucus nigra) and black locust (Robinia pseudoacacia). Plant Physiol. 80:747-751.

Nuotio, S., H. Häggman, and S. Kupila-Ahvenniemi. 1990. Changes in gene expression of Scots pine buds during the winter and under experimentally altered light and temperature conditions. Physiol. Plant. 78:511-518.

O'Kennedy, B.T. and J.S. Titus. 1979. Isolation and mobilization of storage proteins from apple shoot bark. Physiol. Plant. 45:419-424.

Olsen, J.E., O. Junttila, and T. Moritz. 1995. A localised decrease of $\mathrm{GA}_{1}$ in shoot tips of Salix pentandra seedlings precedes cessation of shoot elongation under short photoperiod. Physiol. Plant. 95:627-632.

Olsen, J.E., O. Junttila, and T. Moritz. 1997a. Long-day induced bud break in Salix pentandra is associated with transiently elevated levels of $\mathrm{GA}_{1}$ and gradual increase in indole-3-acetic acid. Plant Cell Physiol. 38:536-540.

Olsen, J.E., O. Junttila, J. Nilsen, M.E. Eriksson, I. Martinussen, O. Olsson, G. Sandberg, and T. Moritz. 1997b. Ectopic expression of oat phytochrome A in hybrid aspen changes critical daylength for growth and prevents cold acclimatization. Plant J. 12:1339-1350.

Oppenheimer, C.H. and E. Slor. 1968. Breeding of apples for a subtropical climate. II. Analysis of two $\mathrm{F}_{2}$ and nine backcross populations. Theor. Appl. Genet. 38:97-102.

Pauley, S.S. and T.O. Perry. 1954. Ecotypic variation of the photoperiodic response in Populus. J. Arnold Arbor. 35:167-188.

Perry, T.O. 1971. Dormancy of trees in winter. Science 171:29-36.

Powell, L.E. 1987. Hormonal aspects of bud and seed dormancy in temperatezone woody plants. HortScience 22:845-850.

Reid, J.L. and M.K. Walker-Simmons. 1990. Synthesis of abscisic acidresponsive, heat-stable proteins in embryonic axes of dormant wheat grain. Plant Physiol. 93:662-667.

Riemenschneider, D.E., B.G. McMahon, and M.E. Ostry. 1994. Populationdependent selection strategies needed for 2-year-old black cottonwood clones. Can. J. For. Res. 24:1704-1710.

Rodriguez-A, J., W.B. Sherman, R. Scorza, M. Wisniewski, and W.R. Okie 1994. 'Evergreen' peach, its inheritance and dormant behavior. J. Amer. Soc. Hort. Sci. 119:789-792.

Rohde, A., W. Ardiles-Diaz, M. van Montagu, and W. Boerjan. 1998. Isolation and expression analysis of an ABSCISIC ACID-INSENSITIVE 3 (ABI3) homologue from Populus trichocarpa. J. Expt. Bot. 49:1059-1060.

Rohde, A., G.T. Howe, J.E. Olsen, T. Moritz, M. Van Montagu, O. Junttila, and W. Boerjan. 1999. Molecular aspects of bud dormancy in trees. In: S.M. Jain (ed.) Molecular biology of woody plants. Kluwer, The Netherlands. (In press.)

Rohde, A., M. Van Montagu, D. Inze, and W. Boerjan. 1997. Factors regulating the expression of cell cycle genes in individual buds of Populus. Planta 201:43-52.

Rowland, L.J. and R. Arora. 1997. Proteins related to endodormancy (rest) in woody perennials. Plant Sci. 126:119-144.

Sorensen, F.C. 1983. Relationship between logarithms of chilling period and germination or bud flush rate is linear for many tree species. Forest Sci. 29:237-240.

Stafstrom, J.P., M. Altschuler, and D.H. Anderson. 1993. Molecular cloning and expression of a map kinase homologue from pea. Plant Mol. Biol. 22:83-90.

Stafstrom, J.P. and I.M. Sussex. 1988. Patterns of protein synthesis in dormant and growing vegetative buds of pea. Planta 176:497-505.

Stafstrom, J.P. and I.M. Sussex. 1992. Expression of a ribosomal protein gene in axillary buds of pea seedlings. Plant Physiol. 100:1494-1502.

Stepien, V. and F. Martin. 1992. Purification, characterization and localization of the bark storage proteins of poplar. Plant Physiol. Biochem. 30:399-407.

Stepien, V. and J.J. Sauter. 1994. Ringing induces the accumulation of vegetative storage proteins in poplar bark. Trees 9:88-92.

Stepien, V., J.J. Sauter, and F. Martin. 1992. Structural and immunological homologies between the storage proteins in the wood and the bark of poplar. J. Plant Physiol. 140:247-250.

Stepien, V., J.J. Sauter, and F. Martin. 1994. Vegetative storage proteins in woody plants. Plant Physiol. Biochem. 32:185-192.

Tanksley, S.D. 1993. Mapping polygenes. Annu. Rev. Genet. 27:205-233.

Tanksley, S.D., N.D. Young, A.H. Paterson, and M.W. Bonierbale. 1989. RFLP mapping in plant breeding: New tools for an old science. Bio/ Technology 7:257-264.

Thomas, B. 1991. Phytochrome and photoperiodic induction. Physiol. Plant. 81:571-577.

Thompson, M.M., D.C. Smith, and J.E. Burgess. 1985. Nondormant mutants in a temperate tree species, Corylus avellana L. Theor. Appl. Genet. 70:687-692.

Titus, J.S. and S.-M. Kang. 1982. Nitrogen metabolism, translocation, and recycling in apple trees., Hort. Rev. 4:204-246.

van Cleve, B. and K. Apel. 1993. Induction by nitrogen and low temperature of storage-protein synthesis in poplar trees exposed to long days. Planta 189:157-160.

van Cleve, B., S. Clausen, and J.J. Sauter. 1988. Immunochemical localization of a storage protein in poplar wood. J. Plant Physiol. 133:371-374.

van der Schoot, C. 1996. Dormancy and symplasmic networking at the shoot apical meristem, p. 59-81. In: G.A. Lang (ed.). Plant dormancy: Physiology, biochemistry and molecular biology. CAB Intl., Wallingford, U.K.

Wang, S.Y., H.J. Jiao, and M. Faust. 1991. Changes in the activities of catalase, peroxidase, and polyphenol oxidase in apple buds during bud break induced by thidiazuron. J. Plant Growth Regulat. 10:33-39.

Wetzel, S., C. Demmers, and J.S. Greenwood. 1989. Seasonally fluctuating bark proteins are a potential form of nitrogen storage in three temperate hardwoods. Planta 178:275-281.

Williams, C.G. 1998. QTL mapping in outbred pedigrees, p. 81-94. In: A.H. Paterson (ed.), Molecular dissection of complex traits. CRC Press, Boca Raton, Fla.

Zimmerman, R.H. and M. Faust. 1969. Pear bud metabolism: Seasonal changes in glucose utilization. Plant Physiol. 44:1273-1276. 